\title{
Structure and mechanical properties of steels for thermochemical treatment
}

\author{
Baya Melik $^{1 *}$, Mostapha Iezid ${ }^{2}$, Fayçal Goumeidane ${ }^{3}$, Messaoud Legouera $^{4}$ \\ ${ }^{1}$ Laboratoire de Génie Mécanique et Matériaux, Université de Skikda, 21000, Algerie \\ ${ }^{2}$ Laboratoire de Génie Mécanique, université de Biskra, BP 145, Biskra, Algerie \\ Email: melikbaya@yahoo.fr
}

\begin{abstract}
In this study, we are interested in a preliminary characterization of the NV10 steel for the thermochemical treatment. A spectral analysis was done to determine the chemical composition of two NV10 nuances rich and poor in micro-alloying elements. Metallographic characterization allows us to examine the structures and the evaluation of the mean grain diameter. XRD is introduced a supplementary basis for the study of the structure the hardness measurements have been developed in addition to the impact tests at low temperature and traction in both directions of the transverse and longitudinal rolling.
\end{abstract}

Keywords: Thermo-chemical Treatment, Mechanical Properties, Steel.

\section{INTRODUCTION}

Metallurgy has always tried to meet the technical and economic requirements imposed by the development of scientific evolution. Thus, dispersive steels find considerable economic importance as a result of the many studies they have carried out [1]. The industrial application of steels with a ferrite-perlite structure resulted in a change in chemical composition towards a lower carbon content and a higher manganese content [2]. The addition of $\mathrm{Nb}$ and $\mathrm{V}$ to obtain hardening precipitation [4] and obtaining a fine-grained structure [7], while maintaining good values of resilience even at low temperature and excellent workability and welding. The mastery of the controlled rolling technique allows to obtain an efficient range of microalloyed steels with $\mathrm{Nb}, \mathrm{V}$ and $\mathrm{Ti}$ [6]. The dispersoide elements dissolved in austenite at high temperature can precipitate under different cooling conditions. By maintaining in the temperature domain corresponding to the transformation $\gamma \alpha$, the precipitation took place in the products of the transformation; The particles formed are very often arranged in two-dimensional sheets parallel to the ferrite-austenite interface. Our work deals with the characterization of two grades of NV10 steels, obtained by controlled rolling, one rich in micro-alloy elements $\mathrm{Nb}, \mathrm{V}$ and the other poor. The chemical composition of the studied steels was demonstrated by spectral analysis. The structure was revealed on the one hand by metallographic examination and on the other side by X-ray diffraction. Tensile tests in the rolling direction as well as in the transverse direction, in addition to the resilience tests Made of the ambient temperature up to $-500 \mathrm{C}$, allowed us to know the static and dynamic behavior of the steels.infact, measuring hardness and microhardness to evolve the hardening effect of applied thermomechanical treatment. This characterization constitutes basic data, such steels undergoing thermo-mechanical treatments, which will undergo subsequent thermochemical treatments. this perspective, we are interested to have the level of superficial hardening that can be obtained on a matrix already hardened.

\section{PROCEDURE}

\subsection{Spectral analysis}

Spectral analysis aims to determine the chemical composition of the two NV10 steels studied. It relies on the separation of the different wavelength radiation by means of a prism from an illuminated slot located at the focal point of the collimator lens. The beam scattered by these prisms and then taken up by a chamber lens which forms on a photographic plate spectral lines characteristic of each alloy element.

\subsection{Metallographic examination}

After the metallographic preparation of the samples, the examination of an optical microscope was done.

\subsection{X-Ray diffraction}

This technique remains complementary to the metallographic examination, the two micrographs shown in FIGS. 1 and 2 associated with the shade of a philips diffractometer at low pitch and with a computer-controlled copper anticathode. 


\subsection{Hardness}

The hardness is obtained by a universal durometer of the Wolpert type, while the microhardness is measured by a Vickers controllable type microduremètre.

\subsection{Tensile test}

The tensile tests were carried out on specimens made in the direction of rolling and the transverse direction. A hydraulic slave machine was used, the force being transmitted by hydraulic jack. The machine is controlled by a computer, the processing of the data is done in real time, the ZWICK Z1011 is used as a software.

\subsection{Resilience Testing}

The test consists of a single stroke of a pendulum sheep, standard specimens (standard API) and notched in V. the resilience was made at low temperature ( $\mathrm{T}$ direction), the specimens are cooled with A SINTCO type freezer, for a holding time of 15 minutes at each temperature which varies from ambient to $-50^{\circ} \mathrm{C}$.

\section{RESULTS AND DISCUSSION}

Table 1. Represents the chemical composition of the two steels

\begin{tabular}{ccl}
\hline & NV10 riche & NV10 pauvre \\
\hline $\mathrm{C} \%$ & 0,203 & 0,159 \\
\hline $\mathrm{Mn} \%$ & 1,298 & 1,108 \\
\hline $\mathrm{Si} \%$ & 0,217 & 0,150 \\
\hline $\mathrm{P} \%$ & 0,0183 & 0,0196 \\
\hline $\mathrm{S} \%$ & 0,009 & 0,020 \\
\hline $\mathrm{Cu} \%$ & 0,029 & 0,031 \\
\hline $\mathrm{Ti} \%$ & 0,008 & 0,003 \\
\hline $\mathrm{Nb} \%$ & 0,051 & 0,014 \\
\hline $\mathrm{V} \%$ & 0,06 & 0,002 \\
\hline $\mathrm{Mo} \%$ & 0,010 & 0,011 \\
\hline $\mathrm{Ni} \%$ & 0,017 & 0,024 \\
\hline
\end{tabular}

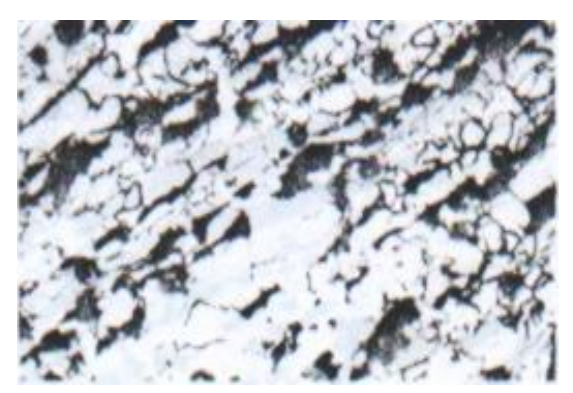

Figure 1. Ferrito-perlitic structure (nital attack 4\%) for steel X52 (transverse direction)

The two micrographs present in FIGS. 1 and 2 associated with the lean and rich grade respectively. They show that the structure is ferrito-perlitic in strip from the effect of controlled rolling [6], The diffraction spectrum X (FIG. 3) is in agreement with the metallorgraphic examination findings. As a result of the existing elements of microalloys $\mathrm{N}, \mathrm{V}, \mathrm{Ti}$, in homeopathic quantities, then the detection of their precipitates requires more sensitive investigative techniques, in particular transmission electron microscopy. This technique remains very useful in the case of very fine or even ultrafine precipitates, carbonitrides of $\mathrm{Nb}, \mathrm{V}$ and $\mathrm{Ti}$ [5].

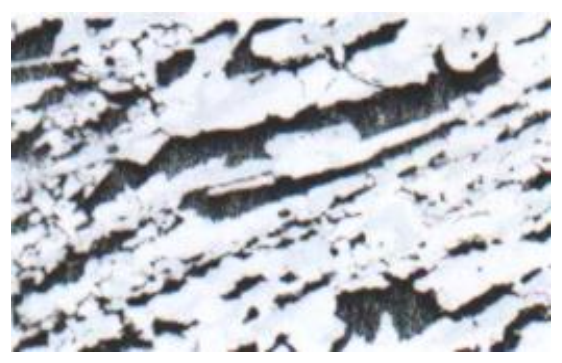

Figure 2. Ferrito-perlitic structure (nital attack 4\%) for steel X52 (direction of rolling)

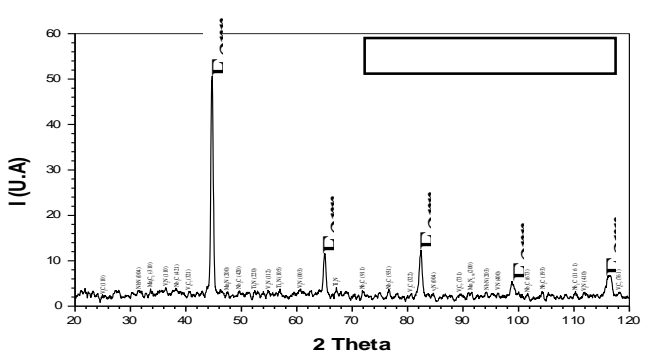

Figure 3. diffraction spectrum $X$

The hardness of the rich NV10 steel reaches $181 \mathrm{HB}$ and the microduct is $289 \mathrm{HV}$, while for the NV10 poor $175 \mathrm{HB}$ and $204 \mathrm{HV}$ grade. The effect of solid solutions (insertion and substitution), fineness of grain size (grain boundary effect), fine precipitation and dispersion in the ferritic matrix $[7,8]$ The difference in curing between the two grades is governed by the quantitative dominance of the main chemical elements that make up the rich NV10 steel.

FIG. 4 shows the variation of the resilience as a function of the temperature which decreases continuously from ambient temperature to $-50 \circ \mathrm{C}$. for both shades. This loss of monotonic ductility is due to the increase of the intrinsic friction of the ferritic matrix, which disturbs the movement of the dislocations in the active planes. This effect is all the stronger in low temperatures, consequently the scission applied to the sliding plane increases [9] and follows the following relation:

$\tau=\tau_{0}+\tau_{1}$

$\tau_{0}$ : critical scission of crystallographic sliding

$\tau_{1}$ : friction stress of the crystal lattice.

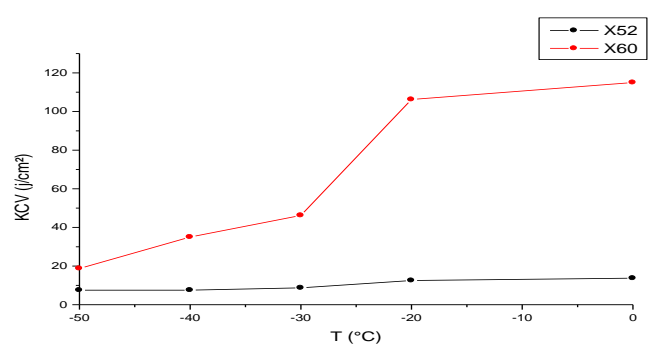

Figure 4. The low temperature resilience of X60, X52 steel

The resilience of the poor shade is better than the rich one, since it is the least hard, therefore the most ductile. Table 2 
summarizes the mechanical properties of the two grades drawn from their traction curves (FIGS. 5, 6, 7). It is clear that the rich NV10 grade is more resistant than the lean shade but from the point of view of ductility it is Conversely, because of the same reasons cited above (grain size precipitation, solid solution effect).

Table 2. The mechanical properties of the two shades

\begin{tabular}{|c|c|c|c|c|}
\hline & $\begin{array}{c}\mathrm{E} \\
\left(\mathrm{KN} / \mathrm{mm}^{2}\right)\end{array}$ & $\begin{array}{l}\mathrm{Re} \\
(\mathrm{MPa})\end{array}$ & $\begin{array}{l}\mathrm{Rm} \\
(\mathrm{MPa})\end{array}$ & A\% \\
\hline $\begin{array}{l}\text { NV10 direction } \\
\text { Riche of rolling }\end{array}$ & 22,3 & 372,8 & 604,9 & 25,89 \\
\hline $\begin{array}{lr}\text { NV10 } & \text { Transverse } \\
\text { Rich } & \text { direction }\end{array}$ & 19,6 & 366,6 & 625 & 22,68 \\
\hline $\begin{array}{cl}\text { NV10 } & \text { Transverse } \\
\text { Poor } & \text { direction } \\
\end{array}$ & e 16,6 & 336,2 & 601,5 & 36,65 \\
\hline
\end{tabular}

The mechanical properties of the two grades Each of the traction curves exhibits a linear elastic (reversible) behavior managed by the famous Hooke law, whose slope is given by Young's modulus E, which estimates the stiffness of the material and depends on the intensity of the chemical bonds. This elastic character begins with a low stress value and ends when a stress threshold is reached, called the elastic limit. When this threshold is crossed, it passes to a plastic behavior (irreversible) or the deformations become permanent. In the first phase, the deformations are homogeneous over the entire sample and then the appearance of the neck or the mode of plastic deformation becomes localized or heterogeneous and the deformation process continues until the sample breaks [4]. The passage from elastic mode to plastic mode is made by activating the sources of Frank-Reed [5], where each dislocation emitted, encounters several obstacles: Frank's network or other emit dislocations, solute atoms which induce Symmetrical and asymmetric distortions of the crystal lattice, the grain boundaries and ultimately the precipitates.

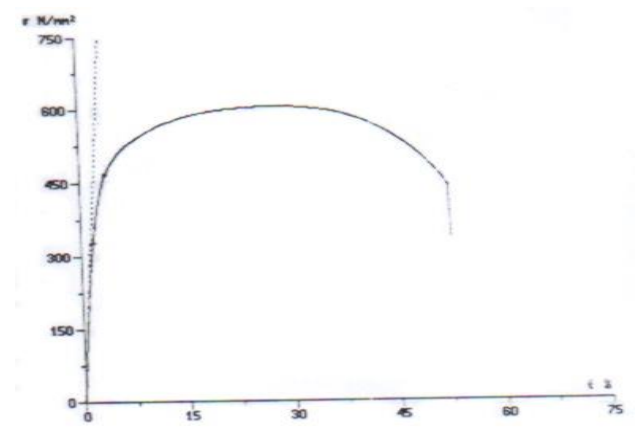

Figure 5. Tension curve No. 01 for steel X60 (direction of rolling)

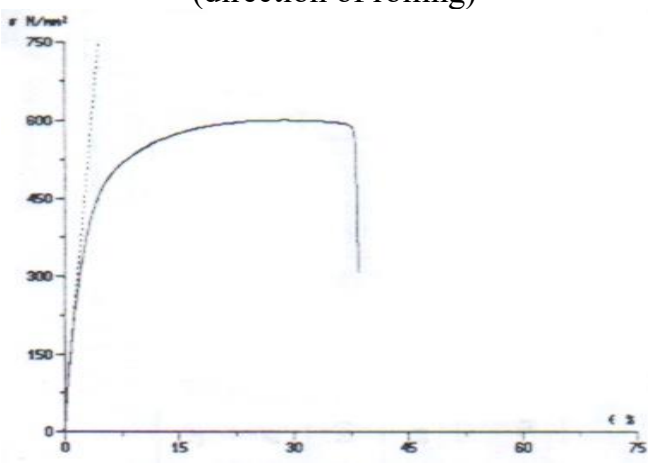

Figure6. Tension curve No. 01 for steel X60 (transverse direction)

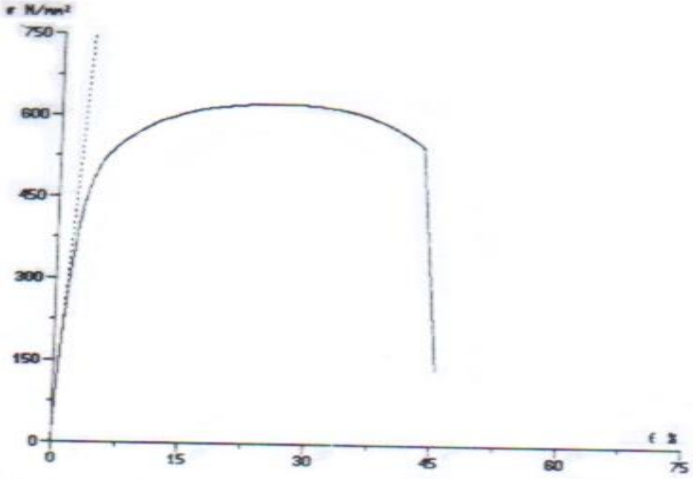

Figure7. Tension curve No. 01 for steel X52 (transverse direction)

\section{CONCLUSIONS}

The steels studied have a ferrito-pearlitic structure in strip due to controlled rolling. They possess fine grain sizes, hence of the thermomechanical treatment applied. On the other hand, the ferritic matrix is hardened by means of dispersing elements NB, V, Ti (in the form of carbonitride). The resilience curves show that the poor Nv10 grade is the most ductile, while the tensile curves and hardness show that the rich NV10 grade is the most resistant

\section{REFERENCES}

[1] Le Bon A. (1979). Le laminage contrôlé des produits plats, RE 689 CIT du CDS, No. 2, pp. 273.

[2] Kunitake T. (1979). Recent development in the field of weldable high strength steel, Metallurgy Companies, pp. 41.

[3] Hori S., Suzuki M., Unigawa Y. (1980). Effect of carbon on the low temperature brittleness of iron, Japan Inst, Metals, No. 2, pp. 55.

[4] Blondeau R. (1980). Les aciers faiblement allies soudable, influence des éléments d'addition soudage et techniques connexes, Janv-Fev, pp. 21-31.

[5] Constant A., et al. (1970). Etude des transformations de l'austenite et de l'évolution des précipités dans les aciers à dispersoides, Conséquences pratiques.Rev. Métallurgie (F), Vol. 67, No. 11, pp. 80-82.

[6] Coolen M.A. (1980). Jeanneau Le laminage contrôlé des tôles fortes, Rev. Métallurgie $(F)$, pp. 112.

[7] Pineau A., François D., Zaoui A. (1996). Comportement mécanique des matériaux, Editions Hermès Paris, pp. 494.

[8] Kelly A., Nicholson R.B. (1971). Strengthening methods in crystals, applied science publishing, Grande Bretagne, pp. 627.

[9] Kelly A., Macmillian N.H. (1986). Strong Solids, Oxford, Grande Bretagne. 